Tohoku J. Exp. Med., 2007, 211, 187-193

\title{
Nicotine Potentiates the Electrical Field Stimulation- Evoked Contraction of Non-Pregnant Rabbit Myometrium
}

\author{
Tuncay Nas, ${ }^{1}$ Süreyya Barun, ${ }^{2}$ GöKce Sevim ÖZtürk, ${ }^{2}$ Ismail Mert Vural, ${ }^{2}$ \\ ZEYNEP SEvim ERCAN ${ }^{2}$ and Yusuf SARIoĞLu ${ }^{2}$ \\ ${ }^{1}$ Department of Obstetrics and Gynecology, Medical School, Gazi University, Ankara, Turkey \\ ${ }^{2}$ Department of Pharmacology, Medical School, Gazi University, Ankara, Turkey
}

Nas, T., Barun, S., Öztürk, G.S., Vural, I.M., Ercan, Z.S. and SarioĞLu, Y. Nicotine Potentiates the Electrical Field Stimulation-Evoked Contraction of Non-Pregnant Rabbit Myometrium. Tohoku J. Exp. Med., 2007, 211 (2), 187-193 — The women who smoke have lower fertility rates which might be due to harmful effects of nicotine on tubal function and menstrual cycle. Although the uterine contractility of the non-pregnant uterus plays an important role in the human reproduction process, the influence of nicotine on the contractile responses in uterus is not known. Nicotine increases the release of neurotransmitters following nerve stimulation both in the central and peripheral nervous system through acting on nicotinic acetylcholine receptors (nAchRs). The aim of this study was to examine whether the electrical field stimulation (EFS)-evoked contraction is altered in rabbit myometrium strips in the presence of nicotine to evaluate the changes in contractility. EFS-evoked contractile responses were recorded from myometrium strips obtained from non-pregnant rabbits in the absence and presence of nicotine. Nicotine led to the increase in the amplitudes of the EFS-evoked contractile responses in a dose-dependent manner. Therefore, the effects of hexamethonium, cadmium, indomethacin, atropine, and $\mathrm{N}_{\omega}$-Nitro-L-arginine methyl ester hydrochloride were tested on the EFS-evoked contractions in the absence or presence of nicotine to clarify the mechanisms of nicotine-induced potentiation in EFS-evoked contractile responses. Indomethacin, a non-selective cyclooxygenase inhibitor, and hexamethonium, a ganglionic blocker, inhibited nicotine-induced increase in EFS-evoked responses, whereas other chemicals produced no effect. These results suggest that nicotine-induced potentiation may be mediated by nAchRs and prostaglandins. In conclusion, failure of quiescence in the uterus due to increased contractility by nicotine might be one of the factors contributing to infertility in female smokers. nicotine; rabbit; myometrium; electrical field stimulation

(C) 2007 Tohoku University Medical Press

Epidemiologic studies have indicated that the women who smoke have significantly lower fertility rates (Zavos 1989). It has been suggested that harmful effects of the smoking might be on the tubal function, embryo transfer, development and viability of ovocyte (Zavos 1989; Pattinson et al. 1991). Nicotine and the other constituents of tobacco may contribute to infertility in a direct or

Received October 10, 2006; revision accepted for publication January 12, 2007.

Correspondence: Tuncay Nas, M.D., Gazi University, Medical School, Department of Obsterics and Gynecol-

ogy Besevler 06510, Ankara, Turkey.

e-mail: tunnas@gazi.edu.tr 
indirect manner in female smokers (Shiverick and Salafia 1999).

Nicotine, which is the principal chemical in tobacco, modulates the neurotransmitter release both in the central and peripheral nervous system (Todorov et al. 1991; McGehee et al. 1995). It has been shown that nicotine increases the release of neurotransmitters following nerve stimulation (Nedergaard and Schrold 1977; Todorov et al. 1991).

The presynaptic nicotinic acetylcholine receptors (nAchRs) have been shown to play a role in the modulation of the release of neurotransmitters (Collier and Katz 1975). The ganglionic nAchRs have also been reported to be involved in the release of neurotransmitters because nicotine-induced release of Ach from the myenteric plexus (Torocsik et al. 1991) or nicotine-induced release of dopamine from the rat striatum (Marshall et al. 1996) was abolished by tetrodotoxin (TTX) which is a blocker of sodium channels. On the other hand, nicotine acts on nAchRs located in nerve terminals, resulting in transmitter release (Digges 1982).

Although there is evidence indicating the contribution of conractile activity of the nonpregnant uterus to reproduction process (Franchin et al. 2002; Mueller et al. 2006a), there are no data available on the effect of smoking or nicotine itself on the uterus contraction. Therefore, this study was designed to investigate the effect of nicotine, the principal chemical in tobacco, on electrical field stimulation (EFS)-evoked contractile responses in rabbit myometrium to clarify whether nicotine leads to a change in the contractility.

\section{Materials and Methods}

The following reagents were obtained from Sigma (St.Louis, MO, USA): atropine, cadmium chloride-1hydrate, hexametonium, indomethacin, L-NAME $\left(\mathrm{N}_{\omega}\right.$-Nitro-L-arginine methyl ester hydrochloride) prazosin and yohimbine. All drugs were dissolved in distilled water except indomethacin and prazosin which were dissolved in $1 \% \mathrm{Na}_{2} \mathrm{CO}_{3}$.

A total of 20 New Zealand white rabbits weighing 2.5 to $3 \mathrm{~kg}$ were used for the experiments. Experiments were performed in agreement with the ethical standards in Helsinki Declaration, and this study was approved by University Ethics Committee for Animals. Non-pregnant rabbits were killed by exsanguination and the uterus was rapidly excised, opened lengthwise, and emptied. Adherent fat and gross connective tissues were removed and uniform longitudinal strips $(30 \times 4 \times$ natural thickness) were prepared from the antimesometrial surface. Each strip was mounted isometrically at $2 \mathrm{~g}$ resting tension in the organ bath containing $15 \mathrm{ml}$ modified Krebs' solution (composition in mmol/l: $\mathrm{NaCl} 125, \mathrm{KCl} 2.4$, $\mathrm{CaCl}_{2}-2 \mathrm{H}_{2} \mathrm{O} 1.8, \mathrm{MgCl}_{2}-6 \mathrm{H}_{2} \mathrm{O} 0.5, \mathrm{NaHCO}_{3} 23.9$, and glucose 11.0. The $\mathrm{pH}$ of the solution was 7.4 after being bubbled with the gas mixture of $95 \% \mathrm{O}_{2}$ and $5 \% \mathrm{CO}_{2}$ and the solution was maintained at $37^{\circ} \mathrm{C}$. Tissues were allowed to equilibrate for at least $30 \mathrm{~min}$ prior to experimental procedures.

Isometric contractions were evoked by EFS through a pair of platinum electrodes, with $4 \mathrm{~Hz}$ trains of impulses of $1 \mathrm{msec}$ duration for 10 -sec delivered every $2 \mathrm{~min}$. Pulses of $1 \mathrm{msec}$ duration with a voltage of $60 \mathrm{~V}$ were delivered by a stimulator (S48, Grass Instruments, Quincy, MA, USA). EFS-evoked responses were recorded via Grass isometric force displacement transducers (FT 03, Grass Instruments) connected to an ink writing oscillograph (Grass $79 \mathrm{E}$ ) via a preamplifier. Following $30 \mathrm{~min}$ after the EFS-evoked responses reached steady state, nicotine was applied to preparations and after 5 contractions EFS was ceased and the preparation was washed four times every $10 \mathrm{~min}$ for $30 \mathrm{~min}$. EFS was delivered to the tissue after washing and the same experimental procedure was repeated 2-3 times in the same tissue. Nicotine at varying concentrations $(3 \times$ $10^{-5} \mathrm{M}, 1 \times 10^{-4} \mathrm{M}, 3 \times 10^{-4} \mathrm{M}$ ) was applied to each preparation. To test the contribution of adrenergic and cholinergic components to the EFS-evoked responses, the tissue was treated with $\alpha_{1}$ or $\alpha_{2}$ adrenergic receptor blockers, prazosin $\left(1 \times 10^{-5} \mathrm{M}\right)$ or yohimbine $\left(1 \times 10^{-6} \mathrm{M}\right.$ and $\left.1 \times 10^{-5} \mathrm{M}\right)$, respectively and a muscarinic receptor blocker, atropine $\left(1 \times 10^{-6} \mathrm{M}\right)$, for $30 \mathrm{~min}$ before EFS and the same experimental procedure was repeated in the presence of these chemicals. Effects of cadmium $\left(\mathrm{Cd}^{2+}\right)$ (1x $10^{-5} \mathrm{M}, 3 \times 10^{-5} \mathrm{M}$ and $1 \times 10^{-4} \mathrm{M}$ ), indomethacin, a non-selective cyclooxygenase inhibitor, $\left(1 \times 10^{-5} \mathrm{M}\right)$, L-NAME $\left(1 \times 10^{-4} \mathrm{M}\right)$ and hexamethonium, a ganglionic blocker, $\left(1 \times 10^{-5} \mathrm{M}\right)$, each of which was applied $30 \mathrm{~min}$ before nicotine treatment, were also tested on the EFSevoked responses. Effect of nicotine was examined on the preparations in the organ bath at $2 \mathrm{~g}$ resting tension. 
Statistics

Experimental values were expressed as mean \pm S.E.M. Groups were compared statistically using general linear models of ANOVA followed by Bonferroni test. Values of $p<0.05$ were considered to be significant statistically.

\section{Results}

In the present experiments, EFS evoked contractile responses in rabbit myometrium in the absence or presence of nicotine (Fig. 1A).

Nicotine led to increase in the amplitudes of the EFS-evoked contractile responses (Fig. 1A). This effect was concentration dependent $\left(3 \times 10^{-5}\right.$ $\left.\mathrm{M}, 1 \times 10^{-4} \mathrm{M}, 3 \times 10^{-4} \mathrm{M}\right)(n=7)$ (Fig. 1B).

$\operatorname{TTX}\left(1 \times 10^{-6} \mathrm{M}, n=2\right), \mathrm{Cd}^{2+}\left(1 \times 10^{-5} \mathrm{M}\right.$,

A

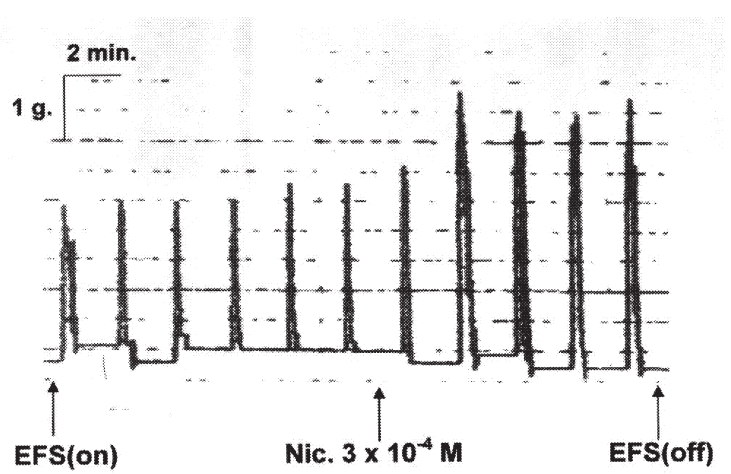

B

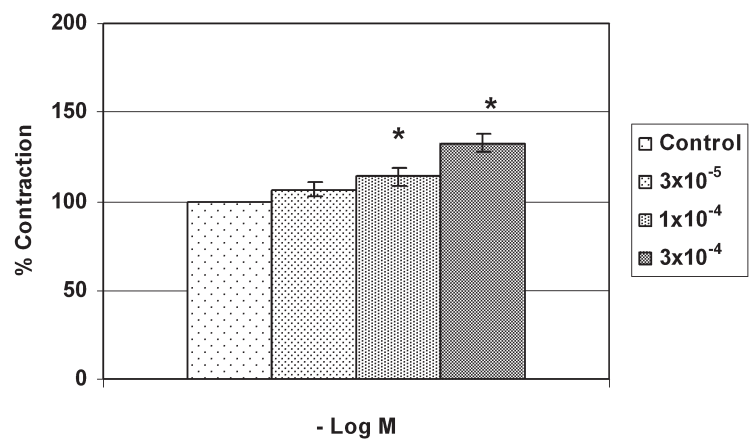

Fig. 1. Typical tracing showing the effect of nicotine on the EFS-evoked responses in nonpregnant rabbit myometrium (A) and effects of the different concentrations of nicotine on the EFS-evoked responses (B). Each point is expressed as a percentage of the control and is given as the mean \pm S.E.M. $\left({ }^{*} p<0.05\right)$.

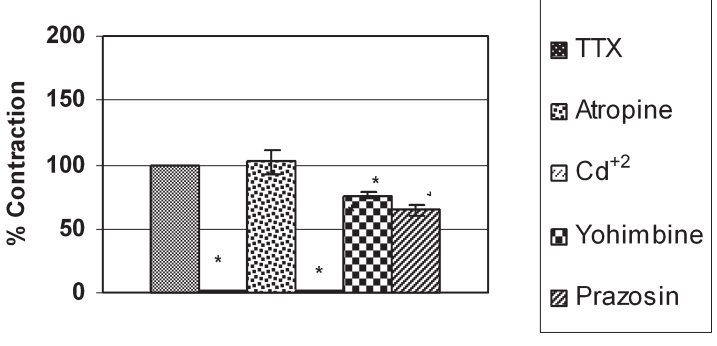

Fig. 2. Effects of TTX, atropine, $\mathrm{Cd}^{+2}$, yohimbine and prazosin on the EFS-evoked contractile responses. Each point is expressed as a percentage of the control and is given as the mean \pm S.E.M. $\left({ }^{*} p<0.05\right)$.

$n=6)$, indomethacin $\left(1 \times 10^{-5} \mathrm{M}, n=8\right)$, prazosin $\left(1 \mathrm{x} 10^{-5} \mathrm{M}, n=6\right)$ and yohimbine $\left(1 \times 10^{-6} \mathrm{M}\right.$ and $\left.1 \mathrm{x} 10^{-5} \mathrm{M}, n=6\right)$ significantly decreased EFSevoked contractile responses, while atropine $\left(1 \mathrm{x} 10^{-6} \mathrm{M}, n=8\right)$ and L-NAME $\left(1 \times 10^{-4} \mathrm{M}, n=7\right)$ had no effect (Fig. 2).

Indomethacin and hexamethomium inhibited nicotine-induced increase in EFS-evoked responses (Fig. 3A, 3C), whereas other chemicals produced no effect (Fig. 3B, 3D). Nicotine had no effect, per se, on quiescent preparations which were not applied electrical field stimulation (data not shown).

\section{Discussion}

Myometrium is supplied with both the cholinergic and adrenergic nerves. Cholinergic activity produces contraction of the myometrium while the adrenergic stimulation leads to the contraction and relaxation through the $\alpha$ - (excitatory) and $\beta_{2^{-}}$ (inhibitory) aderenoceptors (Marshall 1970; Bulat et al. 1989). Nerve stimulation studies have provided evidence in support of intraspecies differences in functional innervation of the uterus. Adrenergic nerves are dominant in the guinea pig and rabbit uterus, whereas cholinergic nerves are dominant in the rat (Hollingsworth 1975; Elmer et al. 1980; Hoffmann et al. 1981).

In the present experiments, atropine did not antagonize EFS-evoked contractile responses, indicating the lack of cholinergic activity in rabbit myometrium. To evaluate the involvement of 
A

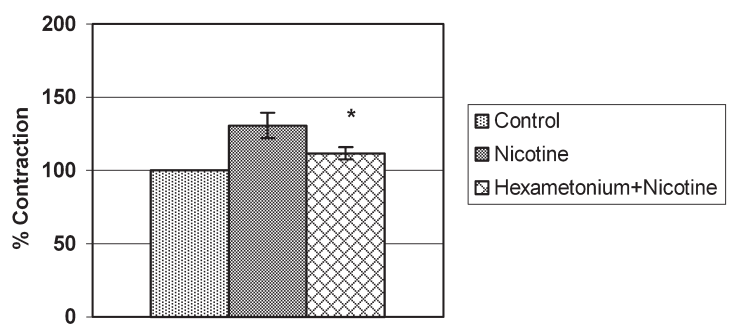

B

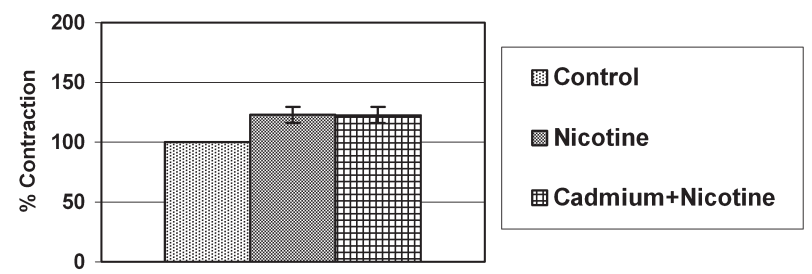

$\mathrm{C}$

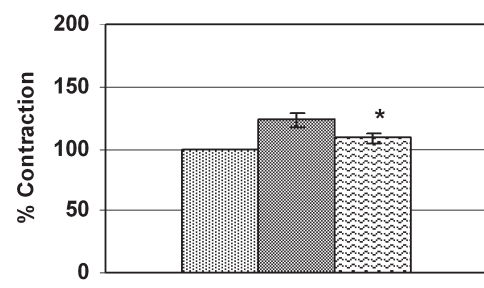

国 Control

Nicotine

İndomethacin+Nicotine

Fig. 3. Effects of the hexametonium (A), $\mathrm{Cd}^{+}$(B), indomethacin (C), L-NAME (D) on the $3 \times 10^{-4} \mathrm{M}$ nicotine induced increase in EFS-evoked contractile responses. Each point is expressed as a percentage of the control and the average of the five EFS-evoked contractile responses and all the points are given as the mean \pm S.E.M. ( $\left.{ }^{*} p<0.05\right)$.

adrenoceptor activation in EFS-evoked contractions, prazosin and yohimbine, were used to block $\alpha_{1}$ and $\alpha_{2}$ adrenoceptors, respectively. These antagonists inhibited the EFS-induced contractile responses, indicating that adrenergic system is prominent in rabbit myometrium as it has been shown previously (Elmer et al. 1980). In support of these findings, both $\alpha_{1}$ and $\alpha_{2}$ have been reported to be excitatory $\alpha$-adrenoceptors in the uterus (Ko et al. 1980; Berg et al. 1986; Marnet et al. 1987; Kaulenas et al. 1991; Clarke and Ruben 1996).

Pharmacological analysis of EFS induced mechanical responses in isolated smooth muscle strips is a useful in vitro technique for clarifying autonomic innervation and contractility. In the present experiments, nicotine-induced potentiation of EFS-evoked contractions was characterized by a rapid onset and an initial, transitory peak. The potentiation was reversible and no tachyphylaxis developed. Although nicotine has been shown to have a facilitatory effect on neurotransmitter release through acting on nAChRs, little is known about the exact mechanisms of this action (Rose et al. 1999; Wang et al. 2000). In consistent with the previous studies, hexamethonium prevented the potentiation caused by nicotine, showing that $\mathrm{nAChRs}$ are responsible for the effect of nicotine (Ritchie 1979; McGehee et al. 1995). On the other hand, the results obtained from another study showing the inhibitory effect of nicotine on EFS-evoked contractions due to predominance of $\beta$-receptors and more responsiveness in the mouse are important for clarifying the differential effect of nicotine between species (Medina et al. 1992).

TTX, a blocker of $\mathrm{Na}^{+}$channels, abolished the EFS-evoked responses. This result supports the involvement ganglionic $\mathrm{nAChRs}$ in nicotineinduced release of neurotransmitters as it has been reported in another study (Koley et al. 1987; Torocsik et al. 1991; Marshall et al. 1996).

The effect of $\mathrm{Cd}^{2+}$ which blocks all known voltage-gated calcium (VGCC) channels involved in the EFS-evoked responses, was tested. Contractions elicited by EFS were abolished by 
$\mathrm{Cd}^{2+}$, showing that VGCC are required for the excitatory neuro-effector transmission in the rabbit myometrium. Lack of effect of $\mathrm{Cd}^{2+}$ on nicotine-induced increase suggest that voltage activated $\mathrm{Ca}^{2+}$ channels do not play a role in the enhancement of EFS-evoked contractions. Possible direct interaction of nicotine with sarcolemmal $\mathrm{Ca}^{2+}$ channels resulting in increased influx of $\mathrm{Ca}^{2+}$ has been reported (Dolezal et al. 1995). Moreover, nicotine increases resting $\mathrm{Ca}^{2+}$ concentration via activation of nAChRs, leading to an effect on the transmitter release (Zucker 1989; Brain et al. 2001; Shoop et al. 2001). Thus, it is likely that nicotine enhances EFS-evoked responses by facilitating NA release by a mechanism independent from the influx of $\mathrm{Ca}^{2+}$ via VGCC. However, it is also probable that following the nAChRs activation, $\mathrm{Ca}^{2+}$ influx occurs via ligand gated channels and causes $\mathrm{Ca}^{2+}$-induced $\mathrm{Ca}^{2+}$-release (CICR), leading to increase in transmitter release (Mulle et al. 1992; Sharma and Vijayaraghavan 2001). In consistent with this view, it has been suggested that activation of nAChRs may lead to sufficient $\mathrm{Ca}^{2+}$ influx via the nicotinic channel itself to promote exocytosis independently of VGCC (Senior et al. 1991).

EFS-evoked responses and nicotine-induced increase in contractions were dimished significantly in the presence of indomethacin suggesting that prostaglandin $(\mathrm{PG})$ release from myometrial cells makes contribution to the responses elicited by EFS in the presence or absence of nicotine. Although it is known that PGs have influence on uterine contractility, different PGs show different contractility patterns (Senior et al. 1992, 1993; Sawdy et al. 1998; Mueller et al. 2006b). On the other hand, receptor expressions for different PGs and myometrial sensitivity has been shown to changed during labour and pregnancy although there is still no data for non-pregnant uterus (Astle et al. 2005). Since limited data are available, further investigation is needed to clarify the contribution of different PGs. Another explanation for the inhibitory effect of indomethacin may be that the blockade of the $\mathrm{Ca}^{2+}$ channel current by indomethacin in myometrium may have contributed to this inhibition (Mirabile et al. 2000).
Inability of L-NAME to antagonize the EFSevoked contractile responses and nicotine-induce increase suggests that nitric oxide release is not involved. In favor of this study, it has been suggested that nitric oxide does not play a physiologic role in the regulation of uterine non-pregnant or pregnant contractility (Barlett et al. 1999). However, data on the function of NO in the contractility of non-pregnant uterus still controversial (Nakanishi et al. 1996).

This is the first study showing the potentiation of EFS-evoked contractions by nicotine in the non-pregnant rabbit myometrium. On the other hand, this study seems important from the clinical point of view since nicotine might contribute to increased rate of infertility which has been shown in women who smoke (Pattinson et al. 1991; Rosevear et al. 1992). Contractile activity of the nonpregnant uterus plays an important role in the human reproduction process (Franchin et al. 2002; Mueller et al. 2006b). Mainstream and sidestream smoking has been shown to cause a significant decrease in the ability of embryos to implant and/or maintain a pregnancy when compared to non-smokers despite being no difference in morphological appearance and development rate of preimplantation embryos from smokers (Neal et al. 2005). Taken together, it seems possible to speculate that failure of quiescence due to increased contractility by nicotine might be one of the factors impairing implantation and contributing to infertility in female smokers as well as its other effects such as impairing oocyte function and viability effect (Zenzes et al. 2000).

In conclusion, nicotine leads to nAchRsmediated increase in the EFS-evoked contractile responses in rabbit myometrium. PGs make contribution to this effect. Although the mechanisms by which nicotine exerts its effects are not known completely, these results provide us with a clue which may have a role in the mechanisms of infertility in female smokers.

\section{References}

Astle, S., Thornton, S. \& Slater, D.M. (2005) Identification and localization of $\mathrm{PGE}_{2}$ receptors in upper and lower segment human myometrium during pregnancy. Mol. Hum. 
Reprod., 11, 279-287.

Bartlett, S.R., Bennett, P.R., Campa, J.S., Dennes, W.J.B., Slater, D.M., Mann, G.E., Poston, L. \& Poston, R. (1999) Expression of nitric oxide synthase isoforms in pregnant human myometrium. J. Physiol., 15, 705-716.

Berg, G., Andersson, R.G.G. \& Ryden, G. (1986) $\alpha$-Adrenergic receptors in human myometrium during pregnancy. Am.J. Obstet. Gynecol., 154, 601-606.

Brain, K.L., Trout, S.J., Jackson, V.M., Dass, N. \& Cunnane, T.C. (2001) Nicotine induces calcium spikes in single nerve terminal varicosities: a role for intracellular calcium stores. Neuroscience, 106, 395-403.

Bulat, R., Kannan, M.S. \& Garfield, R.E. (1989) Studies of the innervation of rabbit myometrium and cervix. Can.J. Physiol. Pharmacol., 67, 837-844.

Clarke, P.B. \& Ruben, M. (1996) Release of [H]-noradrenaline from rat hippocampal synaptosomes by nicotine: mediation by different nicotinic receptor subtypes from striatal [3H]dopamine release. Br. J. Pharmacol., 117, 595-606.

Collier, B. \& Katz, H.S. (1975) Studies upon the mechanism by which acetylcholine releases surplus acetylcholine in a sympathetic ganglion. Br. J. Pharmacol., 55, 189-197.

Digges, K.G. (1982) Adrenoceptors in uterus. J. Auton. Pharmacol., 2, 53-67.

Dolezal, V., Schobert, A. \& Hertting, G. (1995) Presynaptic nicotinic receptors stimulate increases in intraterminal calcium of chick sympathetic neurons in culture. J. Neurochem., 65, 1874-1879.

Elmer, M., Alm, P. \& Thorbert, G. (1980) Electrical field stimulation of myometrial strips from non-pregnant and pregnant guinea-pigs. Acta Physiol. Scand., 108, 209-213.

Franchin, R., Picone, O., Ayoubi, J.M., Marcadet-Fredet, S., Kadoch, J. \& Frydman, R. (2002) Uterine contractility and reproduction: new perspectives. J. Gynecol. Obstet. Biol. Reprod., 31, 325-332.

Hoffman, B.B., Lavin, T.N., Lefkowitz, R.J. \& Ruffolo, R.R., Jr. (1981) Alpha adrenergic receptor subtypes in rabbit uterus, mediation of myometrial contraction and regulation by estrogens. J. Pharmacol. Exp. Ther., 219, 290-295.

Hollingsworth, M. (1975) Mechanical responses of rat isolated uterine horns to transmural stimulation. Br. J. Pharmacol., $\mathbf{5 5}, 41-46$

Kaulenas, A., Parkington, H.C. \& Coleman, H.A. (1991) Response of the rat myometrium to phenylephrine in early pregnancy and the effects of 6-hydroxydopamine. $B r . J$. Pharmacol., 103, 1429-1434.

Ko, J.C.H., Hsu, W.H. \& Evans, L.E. (1980) The effects of xylazine and alpha-adrenoceptor antagonists on bovine uterine contractility in vitro. Theriogenology, 33, 601-611.

Koley, J., Saha, J.K. \& Koley, B.N. (1987) Effects of nicotine on spontaneous contractions of isolated atria of toad (Bufo melanostictus). Arch. Int. Pharmacodyn. Ther., 288, 71-86.

Marnet, P.G., Garcia-Villar, R., Laurentie, M.P. \& Toutain, P.L. (1987) In vivo pharmacological characterization of alpha adrenergic receptors in sheep myometrium and their physiological meaning. Biol. Reprod., 37, 241-248.

Marshall, J.M. (1970) Adrenergic innervation of the female reproductive tract: anatomy, physiology and pharmacology. Ergeb. Physiol., 62, 6-67.

Marshall, D., Soliakov, L., Redfern, P. \& Wonnacott, S. (1996) Tetrodotoxin sensitivity of nicotine-evoked dopamine release from rat striatum. Neuropharmacology, 35, 1531-1536.

McGehee, D.S., Heath, M.J., Gelber, S., Devay, S.P. \& Role,
L.W. (1995) Nicotine enhancement of fast excitatory synaptic transmission in CNS by presynaptic receptors. Science, 269, 1692-1696.

Medina, J.L., Navarrete, C., Lama, C., Roa, A., Cruz, M.A. \& Rudolph, M.I. (1992) Nicotine stimulates adrenergic terminals and inhibits contractions of mouse uterine horns. Gen. Pharmacol., 23, 493-496.

Mirabile, C.P., Jr., Massmann, G.A. \& Figueroa, J.P. (2000) Physiologic role of nitric oxide in the maintenance of uterine quiescence in nonpregnant and pregnant sheep. Am. J. Obstet. Gynecol., 183, 191-198.

Mueller, A., Semer, J., Schreiner, S., Koesztner, H., Hoffmann, I., Binder, H., Beckmann, M.W. \& Dittrich, R. (2006a) Role of estrogen and progesterone in the regulation of uterine peristalsis: results from perfused non-pregnant swine uteri. Hum. Reprod., 21, 1863-1868.

Mueller, A., Maltaris, T., Siemer, J., Binder, H., Hoffmann, I., Beckmann, M.W. \& Dittrich, R. (2006b) Uterine contractility in response to different prostaglandins: results from extracorporeally perfused non-pregnant swine uteri. Hum. Reprod., 21, 2000-2005.

Mulle, C., Choquet, D., Korn, H. \& Changeux, J.P. (1992) Calcium influx through nicotinic receptor in rat central neurons: its relevance to cellular regulation. Neuron, $\mathbf{8}$, 135-143.

Nakanishi, H., Matsuoka, I., Ono, T., Okawa, T., Katahira, K. \& Nakahata, N. (1996) Excitatory response of rabbit myometrium to nitric oxide in vitro. Res. Commun. Mol. Pathol. Pharmacol., 92, 211-224.

Neal, M.S., Hughes, E.G., Holloway, A.C. \& Foster, W.G. (2005) Sidestream smoking is equally as damaging as mainstream smoking on IVF outcomes. Hum. Reprod., 20, 2531-2535.

Nedergaard, O.A. \& Schrold, J. (1977) The mechanism of action of nicotine on vascular adrenergic neuroeffector transmission. Eur. J. Pharmacol., 42, 315-329.

Pattinson, H.A., Taylor, P.J. \& Pattinson, M.H. (1991) The effect of cigarette smoking on ovarian function and early pregnancy outcome of in vitro fertilization treatment. Fertil. Steril., 55, 780-783.

Ritchie, J.M. (1979) A pharmacological approach to the structure of sodium channels in myelinated axons. Аnnu. Rev. Neurosci., 2, 341-362.

Rose, J.E., Westman, E.C., Behm, F.M., Johnson, M.P. \& Goldberg, J.S. (1999) Blockade of smoking satisfaction using the peripheral nicotinic antagonist trimethaphan. Pharmacol. Biochem. Behav., 62, 165-172.

Rosevear, S.K., Holt, D.W., Lee, T.D., Ford, W.C., Wardle, P.G. \& Hull, M.G. (1992) Smoking and decreased fertilization rates in vitro. Lancet, 340, 1195-1196.

Sawdy, R.J., Knock, G., Bennett, P.R., Poston, L. \& Aranson, P. (1998) The effect of nimesulide and indomethacin in contractility and calcium current in myometrial smooth muscle from pregnant women. Br. J. Pharmacol., 125, 1212-1217.

Senior, J., Marshall, K., Sangha, R., Baxter, G.S. \& Clayton, J.K. (1991) In vitro characterization of prostanoid EP-receptors in the non-pregnant human myometrium. Br. J. Pharmacol., 102, 747-753.

Senior, J., Sangha, R., Baxter, G.S., Marshall, K. \& Clayton, J.K. (1992) In vitro characterization of prostanoid FP-, DP-, IPand TP-receptors on the non-pregnant human myometrium. Br. J. Pharmacol., 107, 215-221.

Senior, J., Marshall, K., Sangha, R. \& Clayton, J.K. (1993) In vitro characterization of prostanoid receptors on human myometrium at term pregnancy. Br. J. Pharmacol., 108, 
501-506.

Sharma, G. \& Vijayaraghavan, S. (2001) Nicotinic cholinergic signaling in hippocampal astrocytes involves calciuminduced calcium release from intracellular stores. Proc. Natl. Acad. Sci. USA, 98, 4148-4153.

Shiverick, K.T. \& Salafia, C. (1999) Cigarette smoking and pregnancy I: Ovarian, uterine and placental effects. Placenta, 20, 265-272.

Shoop, R.D., Chang, K.T., Ellisman, M.H. \& Berg, D.K. (2001) Synaptically driven calcium transients via nicotinic receptors on somatic spines. J. Neurosci., 21, 771-781.

Todorov, L., Windisch, K., Shersen, H., Lajtha, A., Papasova, M. \& Vizi, E.S. (1991) Prejunctional nicotinic receptors involved in facilitation of stimulation-evoked noradrenaline release from the vas deferens of the guine pig. Br. J. Pharmacol., 102, 186-190.
Torocsik, A., Oberfrank, F., Sershen, H., Lajtha, A., Nemesy, K. \& Vizi, E.M. (1991) Characterization of somatodendritic neuronal nicotinic receptors located on myenteric plexus. Eur. J. Pharmacol., 202, 297-302.

Wang, M., Okada, S., Murakami, Y. \& Yokotani, K. (2000) Nicotine-induced noradrenaline release from the isolated rat stomach by activation of L- and N-type calcium channels. Jpn. J. Pharmacol., 83, 102-106.

Zavos, P.M. (1989) Cigarette smoking: male and female infertility. Fertil. Contracept. Sex., 17, 133-138.

Zenzes, M.T. (2000) Smoking and reproduction: gene damage to human gametes and embryos. Hum. Reprod., 6, 122-131.

Zucker, R.S. (1989) Short-term synaptic plasticity. Апnи. Rev. Neurosci., 12, 13-31. 